\title{
PROLEGÓMENOS DE LOS CASOS TRÁGICOS ADMINISTRATIVOS
}

\author{
Mauricio Enrique Rodríguez Delgado** \\ Carlos Arturo Duarte Martínez ${ }^{* * *}$ \\ Recibido: Septiembre 20 de 2014 \\ Aprobado: Octubre 24 de 2014
}

\section{RESUMEN}

En este escrito se defiende la idea de que las autoridades administrativas tienen que decidir casos trágicos. Se realiza una exploración y crítica a la doctrina internacional que centra su estudio del caso trágico como un asunto de los jueces. Para ello se resalta que el ejercicio de la función administrativa en el Estado social de Derecho no puede seguir los postulados clásicos del principio de legalidad, sino que exige realizar actividades de planeación en donde tienen aplicación principios constitucionales para justificar sus decisiones aplicando para ello la ponderación. El reconocimiento de la existencia del "caso trágico administrativo" también es resultado de considerar que la realización de la justicia no sólo corresponde a los jueces, sino también a las autoridades administrativas por más que sean en algo responsables de la desigualdad de las sociedades.

\footnotetext{
* Este escrito es un avance del proyecto de investigación titulado "La doctrina del Caso Trágico en la jurisprudencia de tutela de la Corte Constitucional" desarrollado dentro del Grupo de Investigación en Hermenéutica Jurídica del Centro de Investigaciones Socio-Jurídicas "Laureano Gómez Serrano" (CISJGS) y se enmarca en su primer objetivo específico que es caracterizar el caso trágico.

** Abogado de la Universidad Autónoma de Bucaramanga (UNAB). Especialista en Derecho Público, Ciencia Política y Docencia Universitaria de la UNAB; Magister en Derecho Público de la Universidad Externado de Colombia; y Candidato a Doctor en Derecho por la Universidad de Alcalá. Docente de la Universidad Autónoma de Bucaramanga y la Universidad Industrial de Santander. Miembro del Grupo de Hermenéutica Jurídica del Centro de investigaciones Socio-Jurídicas "Laureano Gómez Serrano".

*** Abogado de la Universidad Autónoma de Bucaramanga (UNAB). Docente Auxiliar y miembro del Grupo de Hermenéutica Jurídica del Centro de investigaciones Socio-Jurídicas "Laureano Gómez Serrano" del que es su asistente administrativo.Correo electrónico: cduarte3@unab.edu.co
} 
Palabras claves: Caso trágico, ponderación, administración pública, equilibrio mínino.

\title{
INTRODUCTION TO ADMINISTRATIVE TRAGIC CASES
}

\begin{abstract}
This article defends the idea that administrative authorities have to solve tragic cases. It explores and criticizes the international doctrine that considers the study of tragic cases as a matter of judges. It is pointed out that the exercise of administrative functions within the Social State of Law cannot follow the classical proposals of the rule of law principle. As a matter of fact, it requires planning activities and the implementation of constitutional principles to justify judicial decisions which are based on the weighing up of divergent rules. The recognition of the existence of the "administrative tragic case" is also the result of considering the realization of justice not only by judges, but also by the administrative authorities even if they are somewhat responsible for social inequality.
\end{abstract}

Key words: Administrative tragic case, weighing up, public administration.

\section{INTRODUCCIÓN}

Entender los silencios de la obra jurídica de un filósofo del derecho de la talla de Manuel Atienza es tan complejo como atrevido. Lo primero por cuanto a que el tratamiento de un particular tema en la mente de un autor puede sufrir cambios con el paso del tiempo. Un planteamiento inicial puede ser madurado, cambiado o definitivamente abandonado; proceso que puede reconstruirse según las huellas que van quedando en libros, artículos y demás publicaciones. Pero, en realidad ¿qué hay detrás de cada variación? Si la idea se abandona, ¿era tan mala o intrascendente que no merece ningún interés investigativo? Es arriesgado entender ese cambio o... un silencio. Pero aún estas confusas circunstancias (i) enseñan que la labor iusfilosófica no es una tarea acabada y (ii) revelan el carácter errático que nunca abandona a la actividad humana, más cuando se trata de las ciencias sociales cuyos resultados no son verificables matemáticamente ${ }^{1}$.

1 Por ejemplo, se dice que hubo hasta tres Hans Kelsen, pero antes ello lleva a algunos a reconocer la grandeza del más importante filósofo del Derecho del siglo XX por reconocer sus errores. 
Es un riesgo grande para quien se aventure a husmear en los silencios o elementos residuales de la obras de Atienza. Pocos están al nivel de formación académica, de experiencia investigativa y de madurez intelectual del profesor Atienza para pretender enmendar o adicionar su obra, circunstancia que genera en principio un manto de incredulidad para el lector a quien se quiere convencer de la comprensión de sus vacíos; además se aumenta el margen de error que acompaña al crítico o a aquel que pretende ver lo que el gran autor pasó por encima o rescatar algo de lo desechado. Así la crítica o la complementación que se quiera hacer a la obra de un gran filósofo del Derecho pueden errar en el golpe, y antes de lograr su propósito de hacer progresar el pensamiento jurídico pueden terminar siendo como los fuegos artificiales que se pierden en la inmensidad del cielo oscuro; entonces la osadía del valiente debe acompañarse con mesura y una capacidad de hacerse entender y justificar sus postulados.

\section{PROBLEMADE INVESTIGACIÓN}

La tarea que se emprende en este escrito se inmiscuye en un pequeño silencio en la obra de Manuel Atienza. Consciente de la valiosa labor que se emprende y de los riesgos que la acompañan se busca determinar si ¿Es posible que a la administración pública se le presenten casos trágicos? O lo que es lo mismo, ¿existen casos administrativos trágicos? Este documento es un avance de la investigación "La doctrina del Caso Trágico en la jurisprudencia de tutela de la Corte Constitucional" desarrollada dentro del Grupo de Investigación en Hermenéutica Jurídica del Centro de Investigaciones Socio-Jurídicas Laureano Gómez Serrano (CISJ-GS), y se enmarca en su primer objetivo específico que es caracterizar el caso trágico.

Desde luego este escrito es una invitación al debate, y no un punto concluido.

\section{HIPÓTESIS DE TRABAJO}

Se sostendrá que la administración pública, en el Estado de Derecho constitucional, al tener que llegar a decidir sobre valores jurídicos no se puede esperar más que realice la justicia en sus decisiones, para lo cual deberá indefectiblemente que ponderar. Y siendo los casos trágicos un límite de la racionalidad, en donde la ponderación por proporcionalidad hace agua y en tal virtud no se puede encontrar una respuesta correcta, nada beneficia a la administración para escaparse de los casos trágicos. 
Así también las autoridades administrativas como los jueces deben preocuparse por establecer qué solución es la constitucionalmente menos dañosa. Lo anterior supone, claro está, que el principio de legalidad enarbolado con tanto ímpetu por el Estado de Derecho legal a causa de la seguridad y sosiego que brindaba en la actuación administrativa, pierde sus alcances ante la constitucionalización del Derecho.

\section{ESTRATEGIAMETODOLÓGICA}

Para el desarrollo de la temática este documento se divide en cinco partes. En la primera se esboza sucintamente la definición del caso trágico que se ha desarrollado dentro del presente proyecto de investigación y luego se profundiza en la concepción que de él tiene el profesor Manuel Atienza. Enseguida se expondrán los retos que tiene la administración pública en el Estado de Derecho constitucional destacando las diferencias frente al Estado de Derecho legal. Finalmente se planteará un ejemplo de caso administrativo trágico y se recogerán las conclusiones.

\section{RESULTADOS}

\section{1. ¿Qué es un caso judicial trágico?}

En desarrollo del proyecto de investigación se ha definido al caso trágico como aquel en el que cualquier decisión que se tome conlleva la afectación del núcleo esencial de uno de los principios que colisionan por la superposición de su supuesto de hecho, por lo que uno de ellos pierde su eficacia frente al caso concreto, a pesar de no resultar expulsado del ordenamiento jurídico; y por el contrario, el principio que se realiza en la decisión que se toma sufre un proceso de "absolutización" en él.

Es tradición o se asume normalmente que cuando se habla de caso fácil y difícil se refiere a la práctica judicial. Los trabajos jurídicos en la materia se orientan por esclarecer el modo en que los jueces deben argumentar para los segundos de ellos. Así también entre los pocos autores que reconocen la existencia del caso trágico también se refieren a él como un caso judicial.

Por ejemplo, Zagrebelsky (2011) cuando explica el Caso Serena lo hace dentro de un capítulo que nomina "Los jueces y el derecho" y en su explicación no se muestra interesado en establecer lo que debían hacer o no las autoridades administrativas competentes para quitar la custodia a 
los padres de crianza que habían introducido ilegalmente a Serena a Italia.

Guastini (2007) por su parte propone de manera general una tipología de colisión de principios en concreto, en la que surgen unos cuya aplicación genera una antinomia total-total (caso trágico), que no son la mayoría por cuanto a que lo son quienes tienen características de un conflicto "parcialbilateral", es decir cuando los supuestos de hecho de dos principios se superponen apenas parcialmente. Pero cuando presenta el cómo resolver de manera general los conflictos de principios, señala que la ponderación es "la técnica normalmente utilizada por los jueces constitucionales para resolver un conflicto entre principios constitucionales" (p.636); sin pensar en que si un conflicto de un caso irresoluble puede presentársele o no a la administración.

Zucca (2011), profesor del King's College de Londres, a pesar de que plantea una definición también general del caso trágico como dilema constitucional, presenta el tema, en un corto escrito traducido al español, con un asunto estudiado por la Corte Europea de Derechos Humanos generado por la discusión entre dos ex cónyuges sobre el manejo de unos óvulos fecundados in vitro durante la vigencia de su matrimonio, que vuelven a ser de interés para la mujer después de la extirpación de sus ovarios, ya que solo con ellos podía ser madre natural. Él no dice quién tenía a cargo la guarda de esos óvulos ni qué debería hacer ese guardador ante peticiones contradictorias del exmarido y exmujer sobre el destino que esos óvulos debían tener. Pero reconoce que "[s]i existen los dilemas constitucionales, entonces ni el parlamento, ni los tribunales ni otras instituciones especializadas están óptimamente posicionadas para resolverlos; ninguna institución hallará fácil el sacrificio de un derecho fundamental en el proceso decisorio" (Zucca, 2011, p.12), lo que lleva a pensar que ese proceso decisorio puede ser legislativo, judicial y ¿por qué no administrativo?

Lamentablemente en adelante Zucca (2011) presenta una propuesta de solución cuyos fundamentos tácitamente le dan el adjetivo judicial a su dilema constitucional. A esto hay que sumar que en ese escrito expresamente manifiesta que no es objeto de estudio "los conflictos de derechos fundamentales y otros bienes o intereses constitucionales" ( $p$. 11) pues se interesa en "los conflictos entre reglas que han sido constitucionalmente atrincheradas y que protegen algunos aspectos fundamentales de la libertad individual" (p.12) los que no agotan los enunciados jurídicos que comúnmente maneja la administración pública, 
o al menos no en un conflicto. También no tener su obra completa en la materia $^{2}$, ni en inglés ni en español, es un límite de los autores de este escrito para conocer su total comprensión del caso trágico.

\subsection{Manuel Atienza frente al Caso trágico}

¿Y Atienza qué? En abril de 1997 publica "Los límites de la interpretación constitucional. De nuevo sobre los casos trágicos" en la que delimita la existencia del caso trágico a la sede judicial, puesto que escenifica cómo el juez puede vivir un asunto puesto a conocimiento suyo de manera trágica, que lo es en dos eventos:

a) una situación en que su ordenamiento jurídico le provee al menos una solución correcta (de acuerdo con los valores de ese sistema) pero que choca con su moral;

b) una situación en que el ordenamiento jurídico no le permite alcanzar ninguna situación concreta. (Atienza, 2010c, p.141)

Para Atienza el relevante para el mundo jurídico es el segundo; pero ese artículo es una flor más en el jardín teórico que él ha sembrado. En efecto, su obra registra un importante desarrollo frente al caso trágico, aunque no ha sido el punto que más lo ocupa en filosofía del derecho o teoría jurídica. Pero el especial interés en estudiar a Manuel Atienza radica en que hay una variación entre el punto de inicio de su trabajo sobre el caso trágico y las conclusiones que obtiene y se condensan en su artículo de 1997.

No se trata de la existencia de dos Atienza frente al caso trágico, sino de dos momentos en su construcción conceptual. El primero que es preliminar está representado en su escrito "Sobre lo razonable en el Derecho" de 1989, y la segunda es la madura que empieza con la publicación de "Las razones del derecho" y que alcanza su pleno desarrollo con el artículo de 1997, cuyas conclusiones han sido replicadas posteriormente cuando Atienza habla de casos trágicos.

Veamos en específico cada uno de esos momentos:

\subsubsection{El Caso trágico en "Sobre lo razonable en el Derecho"}

Refiriéndose a los debates entre Dworkin y sus detractores sobre la

2 Se trata de "Constitutional Dilemas- Conflicts os Fundamental Rights in Europe and the US" publicado por Oxford en 2007.

3 En el N: 06 de la Revista de Teoría y Filosofía del Derecho "Isonomía". 
existencia de respuestas correctas en el Derecho, Atienza (1989) plantea que todos ellos han excluido la posibilidad de que existan los casos trágicos. Enseguida señala que "Un caso puede calificarse como trágico cuando, en relación con el mismo, no existe ninguna solución que se sitúe por encima del equilibrio mínimo" (p.101).

Este equilibrio mínimo implica a juicio de Atienza (1989) que una solución frente al caso difícil respete las exigencias esenciales de los principios prima facie en colisión; solución que se encuentra en un punto más próximo a un principio que a otro, ya que no es "un término medio" puesto que "el equilibrio no consiste... en que cada uno ceda «lo mismo»" (p.97). Además la solución que satisfaga el equilibrio mínimo es la que puede verse como la más aceptable por la comunidad o la que suscite un mayor consenso (Atienza, 1989, p.104).

Y dos son las consideraciones, en el entender de Atienza (1989), que llevan a reconocer la existencia del caso trágico:

(i) El aumento de "normas de fin" como caracterización del Estado social de Derecho, y el carácter normativo que adquiere la Constitución encumbrada en la cima de la pirámide jurídica la cual contiene este tipo de enunciados jurídicos, de los cuales los derechos sociales son sus mejores ejemplos.

Posteriormente, en una etapa madura junto con Juan Ruíz Manero ha distinguido en estas normas de fin a las directrices programáticas y a las reglas de fin, que se caracterizan por establecer objetivos a obtener que son considerados como constitucional y legalmente importantes, dejando cierto margen de discrecionalidad -mucho menor en las reglas de fin-a sus destinatarios para alcanzarlos, que suelen ser organismos con legitimación democrática -como la administración pública y el legislador-, contando las directrices, al contrario de las reglas de fin, con condiciones de aplicación indeterminadas (Atienza y Ruíz Manero, 2004).

(ii) La orientación hacia el "equilibrio" por parte de los "órganos jurídicos de decisión", en tanto a la importancia que se les da a los valores últimos. Ese equilibrio debe ser correcto, de modo que genere un consenso ideal o racional; lo que no ocurre en el caso trágico.

Ruíz Manero (2005) -sin quien no se puede entender la obra de Atienza- precisa que esos valores últimos se incorporan al 
ordenamiento jurídico con los principios en sentido estricto que son sus valores superiores y se relacionan con aquellos "derechos que se orientan a la protección de bienes o intereses que se consideran dignos de igual protección para todos y cada uno de los seres humanos... [esto es] intereses del propio titular del derecho"; en adición a los valores utilitarios que incorporan las directrices programáticas que se identifican con "derechos que se orientan a la protección o promoción de bienes o intereses colectivos" (p.351 y $352)$.

Se puede decir de esta primera concepción del caso trágico de Atienza está orientada por un criterio material y no orgánico en tanto a que pone atención en que el origen del caso trágico se halla en los valores introducidos por los principios jurídicos en el Estado constitucional, los que eran impensables o extraños en sus concepciones anteriores. Y aunque Atienza enmarca en el caso trágico como una tercera categoría en el debate Hart-Dowrkin sobre las respuestas correctas en el Derecho -en donde el segundo plantea la existencia de un Juez Hércules que puede encontrarlas-no delimita el caso trágico a un órgano estatal en especial.

\subsubsection{La idea madura de Caso trágico}

En "Las Razones del Derecho" Atienza (2005) toca tangencialmente los casos trágicos a los que define como aquellos "en los que no existe ninguna respuesta correcta, esto es, casos jurídicos que no pueden decidirse si no es vulnerando el ordenamiento jurídico" (p.201) o en los que "no cabe encontrar una solución que no sacrifique algún elemento esencial de un valor considerado fundamental desde el punto de vista jurídico y/o moral" (135).

Como se dijo más atrás el caso trágico se judicializa plenamente en Atienza en 1997. En adelante es válido hablar de "caso judicial trágico". Atienza (2010c) plantea el caso trágico como un límite de la racionalidad jurídica pues el juez está ante un dilema en el que debe escoger la decisión que cause el mal menor posible al ordenamiento jurídico, utilizando para ello los criterios de racionalidad estricta.

Allí Atienza (2010c) niega expresamente la posibilidad de que a la administración se le presenten casos trágicos. En efecto reconoce que algunos casos jurídicos que deben ser decididos por órganos de la administración terminan en decisiones trágicas que son revisadas por los

4 Originalmente fue publicado en 1991 por el Centro de Estudios Políticos y Constitucionales de Madrid. 
jueces, "pero las suyas no serían ya decisiones trágicas (ellos habrían traducido lo trágico a otros términos)" (Atienza, 2010c, p.139). ¿A cuáles?, y ¿cómo y por qué se transforman? Son preguntas que surgen y a las que a partir del texto no se les puede dar respuesta.

Al final del documento nuevamente plantea el reconocimiento de la introducción de derechos de contenido social y económico a las constituciones como causa de origen de los casos trágicos. Y ¿la orientación hacia el "equilibrio"...? También pero se introduce una modificación: ello compete a los órganos judiciales.

A lo largo de ese escrito Atienza también presenta dos ejemplos de caso trágico: la absolución de un joven por el delito de insumisión por parte de un juzgado de Madrid en 1992 y la expulsión de los extranjeros que entran ilegalmente a un Estado en busca de una mejor vida. Atienza (2007) en un artículo de prensa, plantea como caso trágico lo suscitado en torno a la huelga de hambre iniciada por el confeso e irredento etarra Iñaki de Juana Chaos, responsable de la muerte de 25 personas, a quien se decide alimentar forzosamente -había que amarrarlo de pies y manoscuando su muerte era inminente.

Todos estos eventos inmiscuyen derechos de contenido individual, como la autonomía personal en especial, principios en sentido estricto como se vio atrás.

La referencia al extranjero que por su ingreso ilegal se expulsa del país es tocado nuevamente en "Curso de Argumentación Jurídica"; también se presenta como caso trágico el cobro de los créditos hipotecarios impagados en medio de la crisis económica que vive España: se deja a una familia sin hogar por no cumplir una obligación civil a causa de la disminución de ingresos económicos generada por la misma crisis, la que también hace que esta no se extinga totalmente por cuanto el inmueble ha perdido su valor, de modo que subsiste una deuda a pesar del remate de la casa (Atienza, 2013, p.812 y 813).

Y allí se profundiza el criterio de Atienza (2013) de por qué el caso judicial trágico. Escrito a manera de diálogo sostiene el Maestro de Alicante que:

(...) no cabe tener un Derecho perfectamente justo en el contexto de sociedades tan injustas como las nuestras. La conciencia de lo trágico, el sentimiento de pesar o de sacrificio debe cumplir, 
precisamente, la función de recordar a los jueces (a los juristas) su deber (como ciudadanos) de contribuir al cambio social, de manera que disminuya la dimensión de lo trágico en el Derecho. Y si deben -o debemos- tener algo de mala conciencia es porque todos (o casi todos) somos algo responsables (aunque, naturalmente, en grados muy distintos) de esa injusticia de base. (p.814).

En su reciente visita a Bucaramanga ante una serie de preguntas sobre casos trágicos, Atienza (2014) apuntaba su respuesta en el sentido de la anterior cita: ellos son de existencia residual en el sistema jurídico; provienen de fallas del sistema social que no los evita, y se replican en el Derecho que no puede encontrar para ellos una respuesta correcta. Si las sociedades no fueran tan injustas, lo casos trágicos no se darían.

¿Son los gobiernos los causantes de esas fallas sociales? ¿Son ellos a quienes les cabe más responsabilidad en su origen? Si la respuesta es afirmativa vale la pena preguntarse si ¿estando tan inmersa en esas fallas, las soluciones no pueden surgir desde la administración pública? Desde luego que Atienza hace una apuesta muy fuerte por los jueces constitucionales y pareciera tener una irremediable decepción en la rama ejecutiva; tal vez ello es así porque en el Estado constitucional la judicatura tiene la última palabra ${ }^{5}$. Pero ¿puede renunciarse a tener autoridades administrativas respetuosas de los postulados constitucionales? Los autores consideran que no es posible aceptar que no puedan ser mejores de lo que han sido.

\subsection{Administración Pública y Ponderación}

\subsubsection{Un punto de partida hacia los casos administrativos trágicos}

La globalización y el neoliberalismo sin duda alguna han llevado a que el ejercicio de las funciones de los gobiernos nacionales se oriente a la satisfacción de ciertas exigencias económicas que trascienden a las fronteras de los Estados, muy al pesar de las consecuencias gravosas que se imponen a los más relegados de la sociedad. También en el orden interno, los gobiernos satisfacen los grandes intereses de detentar el gran poder en el sistema económico. Las políticas estatales están en gran parte determinadas por una coherencia que se debe guardar hacia esos

5 Al respecto dijo el Juez Jackson "No tenemos la última palabra porque seamos infalibles pero somos infalibles porque tenemos la última palabra". Ver CORTE SUPREMA DE LOS ESTADOS UNIDOS. Caso Brown vs. Allen. 344 U.S. 443,540 (1953). 
modelos de producción; y muchas veces en los gobiernos no se reflejan los intereses de la población en general.

No es que el neoliberalismo haga impracticables los postulados del Estado constitucional y social de Derecho. Se quiere resaltar que el desarrollo de los postulados constitucionales por parte de los órganos de legitimación democrática -en muchos Estados la agenda del legislativo está guiada por los intereses de los gobiernos- se informa por el modelo económico, de modo que no faltarán las veces en que lo jurídicamente válido no sea lo económicamente conveniente; porque el Derecho, como dicen Atienza y Ruíz Manero (2004) "no es un elemento neutral, sino un instrumento que sirve -con relativa independencia de cuáles sean las 'intenciones' de quienes lo manejan-para ocultar o justificar aspectos de la realidad social"' (p.20), la cual incluye muchas desigualdades.

Pero desde luego la economía no es la única que afinca de tragedias al Derecho. La realidad humana es tan rica que de muchas formas se pueden producir casos trágicos. De seguro que en el escritorio de algún funcionario administrativo está por decidirse un caso con las características de trágico.

Ante todos estos eventos, ¿debe aceptarse sin más que la administración pública tome decisiones sin un total apego a los valores del Derecho? No puede renunciarse a que la administración pública en desarrollo de sus funciones, bien sea en la ejecución de políticas públicas o en el reconocimiento de derechos a los particulares, tome decisiones razonables.

Y ¿si en ese camino no encuentra el equilibrio mínimo del que habla Atienza? Si la administración tiene que decidir con base en valores ¿estos tendrían un comportamiento "ambivalente" según quien corresponda aplicarlos de modo que solo generan casos trágicos ante la judicatura? No se cree que ello es así.

\subsubsection{Constitucionalización del Derecho y administración pública}

Un primer paso para visibilizar los retos que tiene la administración pública en el desarrollo de valores constitucionales, pasa por señalar que tal labor no se puede entender bajo su función de "aplicar la ley".

La ley era garantía de libertad en el Estado de Derecho. Fue la respuesta liberal al Ancien régime cuando el desarrollo del Estado se supeditaba a 
la voluntad del Rey. Es una apuesta por hacer previsible la actividad estatal que en el génesis del Estado de Derecho se mostraba un poco fácil comparado el día de hoy. En aquellos tiempos el Estado debía enfocarse en intervenir en lo menos en los asuntos internos del individuo, regulando los elementos básicos para el desarrollo empresarial del señor burgués: positivización de derechos y establecimiento de un sistema judicial que resolviera los conflictos legales-económicos que se le presentaran. La subsunción y la exégesis eran las herramientas que los poderes ejecutivo y judicial debían atender para satisfacer la exigencia del Estado liberal.

Sin embargo, la administración pública no es la misma en el Estado constitucional. En especial se le exige planificar, lo cual de manera particular en Latinoamérica es dramático debido a que se ve hostigada por demandas en diferentes sectores: salud, educación, vivienda o trabajo, por solo citar algunas. Esa generalidad de la ley, esto es su carácter abstracto, satisfacía los temores liberales; pero actualmente resulta encubridora de muchos problemas sociales.

En este contexto el ejecutivo no debe solo aplicar la ley-función propia en el sistema montesquiano- sino tomar decisiones con amplios márgenes de decisión. También la imposibilidad de prever la ley toda actuación de la administración surge cuando se comprende que las normas jurídicas como manifestaciones de lenguaje presentan zonas de penumbra e incertidumbre que hacen que sean el juez y la administración quienes "tengan que crear la norma concreta aplicable al caso" (2008) particular. Es una seña muy particular del Estado constitucional que no solo al juez le corresponda interpretar sino que en tal labor "están incluidos potencialmente todos los órganos del Estado, todos los poderes públicos, todos los ciudadanos y grupos" (Haberle, 2004, 150).

Razón tiene Zagrebelsky (2011) cuando señala que en el Estado constitucional debido a "la multiplicación de leyes de carácter social y temporal" se "pulveriza" el derecho del legislador. (p.37). La supremacía de la legalidad que por tanto tiempo primó en Colombia cede su posición a la supremacía de la Constitución.

Existiendo una relación de subordinación entre la Ley y la Constitución, la administración pública debe estar siempre atenta que el respeto a la primera no implique la negación de la norma superior. Para ello deben tenerse en cuenta varios aspectos: 
(i) En su función de desarrollar la Constitución, dice Bernal Pulido (2007), el legislador cuenta de un "ámbito para estudiar la información técnica de que disponga... y de un ámbito para evaluar las razones políticas que resulten pertinentes, para adoptar las medidas que considere adecuadas para perseguir sus finalidades" (p.728). A uno y otro los denomina ámbito legislativo de apreciación fáctica y de apreciación normativa.

Recuérdese que esta función se sustenta en el principio democrático que inspira las organizaciones jurídico-políticas occidentales desde finales del siglo XVIII; e implica también reconocer que la Constitución tiene diferentes formas de llevarse a cabo, "de manera que casi nunca puede decirse que una ley con tal estructura y contenido es la única posible" (Atienza, 2010a, p.92). Así por ejemplo para promover el empleo, el Estado puede generarlo de propia mano, establecer incentivos o exenciones tributarias a los empleadores, o incluso mermar la cuantía de las prestaciones laborales a fin de ampliar la base poblacional vinculada al sistema laboral.

(ii) A partir de la descentralización administrativa se tiene que el legislador no puede, ni debe regular todos los aspectos que comporta la vida social de los entes territoriales. Es aconsejable que en un país como Colombia, en donde hay una diversidad cultural, social y etnográfica tan enorme se deje a las autoridades locales -Alcalde y Concejo Municipal-el dar respuesta a las necesidades de sus territorios. Las diferencias que se pueden dar entre los pueblos andinos y los de los costeros, por ejemplo, no son pocas.

Pues bien, también las autoridades administrativas territoriales gozan de un ámbito de apreciación fáctica y normativa para desarrollar la Constitución y las leyes, que varían según las disposiciones del propio legislador.

(iii) En esta situación es necesario que las autoridades administrativas tomen "decisiones conforme a la Constitución", para que con sus decisiones también se realice la justicia. La decisión conforme a la Constitución viene a exigirle a la administración que una decisión suya que desarrolle un principio jurídico particular no suponga el sacrificio a inatención de otro con igual importancia.

Esta exigencia de satisfacción conjunta hace que la administración deba indefectiblemente ponderar de modo que realice ella también la justicia 
presente en los principios constitucionales. Esto ha sido reconocido por el propio Consejo de Estado al resaltar que la aplicación de la ley en el Estado social de Derecho debe centrar su objeto en:

la razonabilidad de su aplicación, que consiste en la competencia del intérprete para que esa abstracción genérica, a la que por su propia naturaleza le resulta imposible regular la totalidad de los casos, pueda conducirse hacia su eficacia material de manera tal que la aplicación del precepto legal no niegue sino viabilice la vigencia del derecho.

Así pues, pese a la pululación de valores y/o principios, los cultores del Derecho administrativo, cuyo estudio tradicionalmente se ha hecho desde la legalidad, no pueden ser ajenos a este nuevo desafío ni renunciar al propósito de dar una solución a cada caso, objetivo que se persigue desde la fundación del Estado de Derecho ${ }^{6}$.

Atienza no niega esta situación. En un escrito sobre la razonabilidad que debe acompañar a las decisiones administrativas defiende la idea según la cual "las decisiones de los órganos públicos no se justifica simplemente en razón a la autoridad que las dicta" (Atienza, 2004, pág. 55), sostener lo contrario implica abrazar una concepción formalista del Derecho. Y tratándose de la administración, sus decisiones se justifican por "las razones de fondo que se dan en favor de una determinada opción. Y un acto administrativo no motivado - dice Atienza (2004) - es como si:

una resolución judicial... careciera de antecedentes de hecho y de fundamentos de Derecho o que se limitara a enunciar una serie de hechos y normas sin dar, por ejemplo, ninguna razón de por qué se considera como probado un determinado hecho. (p.60)

Desde luego esta comparación entre la práctica administrativa y la judicial es planteada como un ejemplo para comprender la primera, y para preparar lo que dice después: "motivar una decisión no significa explicarla, sino justificarla". Y ello se replica tanto de las decisiones judiciales como administrativas; entonces "un acto arbitrario no es un acto sin causa sin motivo, sin explicación, sino un acto que carece de razones que lo hagan aceptable, es decir que carece de justificación" (Atienza, 2005, p.61).

6 CONSEJO DE ESTADO. Sala de lo Contencioso Administrativo. Sección Segunda. Subsección "A". C.P.: Gustavo Eduardo Gómez Aranguren. Sentencia del 12 de octubre de 2011. Rad.: 25000-23-25-0002008-01127-01(0292-11). Isaac Sánchez Gómez Vs. CAJANAL 
Así entonces los casos trágicos no pueden ser ajenos a la práctica administrativa. La administración pública tendría en ese evento que proferir un acto administrativo irremediablemente viciado de nulidad, que al ser sometido a control judicial no podría ser anulado judicialmente. ¿No viviría el juez contencioso-administrativo también la tragedia? ¿Qué podría hacer él mejor que una buena administración?

Muy diferente es que la administración no se dé cuenta que está ante un caso trágico; a lo que los ciudadanos no pueden renunciar.

\subsubsection{Ponderación y administración pública}

a. En Atienza: Tampoco Atienza niega que la administración pública deba ponderar, ni mucho menos que su argumentación en la toma de decisiones es puramente subsuntiva. Junto con Ruíz Manero detallan la "ponderación de concreción" que le corresponde a los órganos con legitimación democrática en el desarrollo de las directrices programáticas. En esencia implica la articulación de políticas públicas, y se desarrolla en tres características: (i) parte con el propósito de concretar un objetivo jurídicamente exigido, que no malverse la obtención de otros; (ii) concluye con el establecimiento tanto de reglas de acción como de fin o la obligación para realizar ciertas tareas; (iii) supone amplios márgenes de discrecionalidad, por lo que en principio está fuera de la órbita judicial. (Atienza, 2010b)

Para Atienza no tiene lugar de aplicación la escala tríadica de la ponderación que ha propuesto Alexy en el desarrollo de directrices programáticas, muy a pesar de que para él esos son los únicos principios que se comportan como mandatos de optimización, en cuanto a su satisfacción gradual. En la concepción de Atienza y Ruíz Manero (2004) los principios en sentido estricto se aplican a la manera todo o nada; y a ellos les corresponde una "ponderación en sentido estricto", que se da en tres momentos: (i) la constatación de una situación específica en donde los principios o valores "tiran en direcciones opuestas" a tal punto que es imposible satisfacerlos simultáneamente; (ii) el establecimiento de prioridad de ellos sobre los demás en ciertas circunstancias, y,(iii) la construcción de una regla que traduce deónticamente esa prioridad.

En el establecimiento de esa prioridad tienen lugar de aplicación la ley de la ponderación, la fórmula del peso y las cargas de argumentación.

b. Los tres juicios de decisión en la ponderación de la administración: La temática de este acápite ha sido de interés para diferentes 
administrativistas, que han demostrado lo contrario a Atienza: en la decisión administrativa también cabe la ley de la ponderación. Sarmiento, (2007) profesor de la Universidad Complutense de Madrid, uno de ellos, ha adaptado la escala tríadica del principio de proporcionalidad a las cuestiones administrativas, y propone tres juicios que debe superar toda decisión de la administración para que sea constitucionalmente admisible:

(i) Juicio de idoneidad: se debe comprobar que el acto administrativo es adecuado para alcanzar los fines que justifican la decisión, para lo cual debe existir una relación de causalidad entre el fin perseguido y el medio adoptado en la decisión. El medio debe ser eficaz para alcanzar el fin. Sólo en cuanto a que la medida sea manifiestamente inadecuada para obtener el objetivo propuesto, el acto debe ser anulado judicialmente.

(ii) Juicio de necesidad: la administración debe estudiar que la decisión que toma "debe ser la medida menos lesiva posible para alcanzar los fines que los justifican" (Sarmiento, 2007, p.19). Deben existir medios alternativos con idoneidad similar que afecten menormente la esfera jurídica de quienes resultan afectados, para que el acto respectivo sea anulable. La existencia de alternativa es importante pues anota el profesor español Sarmiento (2007), en control judicial, "el recurrente debe probarla" (p.190).

Y subraya que al ser un juicio negativo, no puede "el juez entrar a sustituir la decisión adoptada por la Administración" (Sarmiento, 2007, p.191). La elección de una entre varias medidas con la misma capacidad de idoneidad y afectación, no puede catalogarse como una decisión arbitraria o desproporcionada que abra las puertas a la intervención judicial. En caso en que no se cuente con un medio que afecte de manera más leve los derechos o el ámbito de los principios en contraposición, la medida adoptada por la administración debe ser catalogada como necesaria.

(iii) Juicio de proporcionalidad en sentido estricto: la administración debe velar porque la decisión que adopta no restrinja en forma desproporcionada los intereses de quienes resulten afectados -de los beneficiarios del fin que se desarrolla en menor grado-. Este juicio implica un balance de los beneficios del interés público y el coste del sacrificio individual que implica la medida administrativa. Requiere tres pasos: a) identificación de las 
"magnitudes en conflicto" de la relación medio-fin; b) asignación de valor a cada magnitud, y c) determinar que cuanto "mayor sea el grado de perjuicio al ciudadano mayor ha de ser la importancia del fin público legalmente tasado"(Sarmiento, 2007, p. 215).

El acto administrativo debe ser declarado nulo si el perjuicio que causa es mayor al bien que causa al objetivo perseguido.

Sarmiento plantea que además de este análisis de eficacia y evaluación del daño, se debe precisar que la medida alternativa esté dentro de las competencias de la autoridad que la adopta y como mandato de optimización que el fin perseguido debe ser aplicado en grado (Sarmiento, 2007).

Esta última referencia recuerda que en estos dos juicios de adecuación y necesidad se sopesan primordialmente las exigencias fácticas de los principios o deberes constitucionalmente que se pretenden desarrollar o cuando más están en pugna. Tras ellos debe reflejarse un óptimo de Pareto según el cual "una situación es eficiente, cuando no puede operarse ningún cambio posible que mejore la posición de alguien, sin desmejorar la posición de otro" (Bernal Pulido, 2007, p.734).

Desde el proyecto que se desarrolla se ha puesto hincapié en el fracaso de obtención del óptimo de Pareto como nota distintiva de los casos trágicos. A causa, como dice Guastini, de la superposición total-total de los supuestos de hecho de los principios que colisionan hay una exclusión entre ellos de tal manera que es imposible que la decisión con la que se resuelve el caso bajo estudio pueda desarrollar de manera conjunta los principios en pugna. Así al buscar una decisión que sea más benigna o cause un menor daño al principio contrario que es derrotado, no lo encuentra. En ese escenario el grado satisfacción-afectación de los principios en el caso en concreto sería inevitablemente intenso-intenso, sin poder obtener una relación distinta.

Desde luego la tesis del profesor Daniel Sarmiento hace que la distinción entre la aplicación de las directrices programáticas y principios en sentido estricto sea más débil de los que unos piensan. Igual toda construcción teórica se justifica en cuanto a que dé claridad a las cosas, lo que logran de sobra Atienza y Ruíz Manero.

Vale permitirse presentar un ejemplo en donde tiene aplicación la proporcionalidad en la toma de decisiones administrativas que desarrollan 
directrices programáticas ${ }^{7}$. Este en síntesis ejemplariza que aquellos principios en casos concretos también pueden orientarse en sentidos propuestos.

Se trata del Acuerdo 100 de 2009 expedido por el Concejo de Bucaramanga, el cual ha tenido resonancia regional, por el proceso disciplinario que se sigue en contra de los once concejales que votaron su aprobación y el Alcalde que presentó la iniciativa ante el Concejo y que lo sancionó, y por su declaratoria de nulidad en primera instancia por parte del Tribunal Administrativo de Santander.

En él se hace una exención parcial a una serie de impuestos municipales al contrato estatal a partir del cual se construye el viaducto de la novena, obra considerada por el Gobierno municipal como esencial para el progreso urbanístico local. Se buscaba así abaratar una obra cuyo costo no tenía precedente en la ciudad.

Esta obra se construye sobre una zona considerada de reserva forestal por la autoridad ambiental en la que además corren dos quebradas, razón por la que se adoptó un diseño de puente atirantado puesto que representa una menor afectación a dicho componente ambiental en la medida en que necesita considerablemente menos pilotes o columnas para sostener el viaducto - lo que se logra con las tirantas-lo que se traduce en un menor transporte de materiales de construcción sobre dicha zona; descartándose un diseño de viaducto por voladizos sucesivos, el cual tenía como ventaja un considerable menor costo frente al puente atirantado (Poco menos de 10 veces el valor de las exenciones propuestas).

En el Concejo de Bucaramanga, durante las discusiones que se oponían a la iniciativa de exención, se dieron dos argumentos. El primero se afincó en el menor valor del viaducto por voladizos sucesivos -sin tener en cuenta las consecuencias que sobre el medio ambiente tenía-. Y el segundo más sopesado y sincero señalaba que uno de los impuestos exentos parcialmente era la estampilla para la protección del adulto mayor, con la que se financian los Centros Vida de atención al adulto mayor en donde se brinda los servicios más esenciales para la supervivencia física y moral de las personas mayores de 60 años más pobres de Bucaramanga. En criterio de las voces opositoras, aprobar lo que quería el Gobierno municipal significaba darle la espalda a un grupo poblacional muy desprotegido.

7 Este caso fue estudiado a profundidad por los estudiantes del Posgrado de Derecho Público de la UNAB, Drs. Carlos Arturo Duarte Martínez, Alexander Cornejo y Carlos Julián Rueda Duarte, en el proyecto de investigación surtido en la misma. 
La colisión de los principios es clara: por un lado está el mandato de "construir las obras que demande el progreso local" (art. 311 C.P.) junto con el deber de "proteger la diversidad e integridad del ambiente" (art. 79 C.P.) y por el otro lograr la igualdad material de unos colombianos que son considerados sujetos de especial protección constitucional habida cuenta de sus condiciones económicas y su avanzada edad (arts. 13 Inc. final y 46 C.P.).

A lo anterior, se respondió por la bancada mayoritaria de gobierno en el Concejo, que un modelo atirantado de puente se constituiría en un icono de la ciudad y un centro turístico.

El argumento del menor valor del puente por bolardos sucesivos como medida que causa menor daño al valor constitucional que es afectado con el Acuerdo 100 no se replica en el proceso contencioso-administrativo adelantado ante el Tribunal Administrativo de Santander en el que se pide su nulidad. En él tampoco se hacen parte ninguno de los afectados con esa medida, para demostrar un particular menoscabo a sus derechos fundamentales por la decisión gubernamental. En este contexto, se declara la nulidad del acto administrativo bajo tres argumentos ${ }^{8}$ :

(i) Se violó el principio de igualdad tributaria pues la exención se dirigió a un único contratista determinable,

(ii) En él no se contempla una renta sustituta con la cual se obtengan los recursos que a causa de la exención parcial se dejan de recaudar. Esta exigencia está prevista en el artículo $7^{\circ}$ de la Ley 819 de 2003, y es una regla que disciplina fiscalmente a las autoridades que tienen competencia para imponer tributos. Este argumento se relaciona con lo expuesto por Atienza y Ruíz Manero del deber de posibilitar la satisfacción conjunta de las normas programáticas.

(ii) No se debe cargar a los más débiles para perseguir el mejoramiento de la vida de la mayoría de los habitantes; o lo que vale decir: es más prioritario lograr la justicia material que el progreso urbanístico de la ciudad.

Lo anterior muestra que el desarrollo urbano no puede darse a costa de los más débiles de la sociedad. En efecto, la decisión de optar por el

8 TRIBUNALADMINISTRATIVO DE SANTANDER. M.P.: Solange Blanco Villamizar. Sentencia del 28 de septiembre de 2011. Rad.: 680012331000-2010-00441-00 (SN). Edgar Suárez y Pedro Nilson Amaya Vs. Municipio de Bucaramanga. 
modelo de puente atirantado satisface el contenido normativo de la Constitución Ecológica, pero resulta desproporcionada la no atención de los medios establecidos por el legislador para hacer menos fuertes las diferencias que por la edad y carencia de recursos enfrentan las personas de más edad en Colombia. El error de la administración municipal de Bucaramanga consistió en moverse dentro del ámbito de apreciación normativa ante una sin salida en el margen de apreciación fáctica o técnica que le indicaba una sola opción que respetara la integridad del medio ambiente.

La carencia de recursos económicos para la realización del proyecto en particular no podía superarse a costa de los más débiles, cuya participación en los ámbitos decisorios no se refleja. Antes de recargarles el desarrollo de Bucaramanga a ellos, las mayorías representadas en el Alcalde electo y del Concejo de Bucaramanga debieron poner un pie en alto en el desarrollo del proyecto, o asumir las cargas que implican el desarrollo.

Con este ejemplo se ha querido reconocer los estrechos márgenes de acción con los que pueden contar los países con limitados recursos económicos para satisfacer las demandas sociales. Es decir, que los márgenes de capacidad, necesidad y oportunidad que caracterizan el desarrollo de las normas programáticas alguna vez perderán su amplitud y nada impide que se generen eventos en los que la administración se halle como Odiseo: entre Escila y Caribdis.

\subsection{Un ejemplo de un caso administrativo trágico}

No se podría agotar el tema de este escrito si no planteara un ejemplo de un caso trágico para la administración, aunque es hipotético.

La entrada en vigencia de la Constitución de 1991 supuso el reconocimiento del pluralismo étnico y cultural de la mano con la consagración de derechos y principios en favor de los grupos étnicos y afrodescendientes, que por tanto tiempo fueron desconocidos por el Estado colombiano. A partir de principios constitucionales y de convenios suscritos por Colombia ante la Organización Internacional del Trabajo, la Corte Constitucional reconoció en la Sentencia de Unificación 039 de 1997 la existencia del derecho fundamental a la consulta previa en cabeza de las comunidades indígenas y afrodescendientes. 
En síntesis este derecho lleva a que el Estado deba incluirlos en la toma de decisiones que los puedan afectar, como por ejemplo el llevar a cabo proyectos de explotación de recursos naturales en sus territorios. Se pretende así la articulación de dos mundos: el occidental en el que se desenvuelve la sociedad colombiana, y el indígena o afrocolombiano que puede regirse bajo parámetros totalmente inexplicables para el razonamiento occidental.

Sin embargo, ¿Qué tendría que hacer el Gobierno Nacional -en sus diferentes organismos- si consultándole una y 1000 veces a esas comunidades se obtuviera siempre una respuesta negativa para el desarrollo de un proyecto en particular, sin que esta pudiera ser diferente debido a su particular cosmovisión?

Desde luego, que a quién se le pregunte ensayaría alguna respuesta con argumentos fuertes para apoyar una $\mathrm{u}$ otra posición. No pareciera reconocerse nada de trágico al exigir el respeto de la comunidad indígena o por el contrario enarbolar el interés general presente tras el desarrollo del proyecto por parte del Estado. Las posturas serían claras y extremas que se minimizarían las consecuencias gravosas de acoger una u otra posición.

Porque la obtención de recursos económicos por parte del Estado colombiano es necesaria para la satisfacción de todos los derechos constitucionales: la seguridad requiere enorme financiación, lo mismo que los derechos sociales. ¿Cómo se construirá un millón de viviendas gratis si no es con dinero? Con solo propósitos no se logra una cobertura universal y equitativa del plan obligatorio de salud. ¿Con qué se van a cumplir los acuerdos que se establezcan en las negociaciones del proceso de paz de La Habana?

Y por el contrario, ¿en esta colisión se observaría un real cambio del Estado colombiano de la Constitución de 1991 frente a las comunidades indígenas y afrocolombianas, respecto a la Constitución de 1886 ? De no ser así, de nuevo, como antaño, la tensión se rompería en desmedro de la parte débil, los indígenas inferiores numéricamente.

No se piense que ir a explotar recursos naturales a otro sitio es un medio alternativo para obtener riqueza. Tal postura solo haría obviar el problema, sin solucionarlo. Recuérdese que la argumentación jurídica siempre pone su atención en casos concretos y particulares. ¿Qué medida le permitiría al Gobierno ser como los argonautas y superar indemne a Escila y Caribdis? 
Ante un caso trágico la Corte Constitucional -siguiendo de cerca a Manuel Atienza-, estableció en la Sentencia T-458 de 1997 el principio del menor daño constitucional según el cual "ante consecuencias nocivas de cualquier decisión que se le pretenda dar la tarea del juez consiste en identificar y darle curso a la decisión que tenga el menor costo constitucional. En otras palabras, la que produzca el menor daño, desde una perspectiva constitucional"."

Esta sentencia se suscribe en septiembre de 1997, meses después de la aparición del referido artículo de Atienza que lo fue, como ya se dijo, en el mes de abril de ese año. Allí Atienza (2010c) esboza que para la solución de los casos trágicos debía aplicarse la regla del menor daño constitucional. Para el Maestro de Alicante:

[e]l hecho de que no exista una respuesta que pueda calificarse de correcta o de buena, no quiere decir que todas las posibles alternativas sean equiparables... de manera que lo que debemos -lo que un juez debe- hacer en tales situaciones es, sencillamente, optar por el mal menor. (Atienza, 2010c, p.150)

Pero Atienza no hace más que recoger la experiencia de la tragedia griega, pues esa regla del menor daño se encuentra en el consejo que Cirene da a Odiseo o Ulises para superar el estrecho de Mesina: es mejor acercarse a Escila pues a pesar de perder seis marineros - uno atrapado en cada boca del monstruo- puede completar su viaje, y no a Caribdis que hace naufragar y perecer a toda embarcación que se le acerque.

Y ¿cómo aplicar esa regla hermenéutica al caso hipotético propuesto? Para su respuesta surge otra pregunta: ¿Quién es más capaz de superar esa tragedia: la sociedad colombiana o la comunidad indígena o afrodescendiente? Creo que para la primera el no desarrollo de ese proyecto de ninguna manera implicaría la completa negación de su existencia; por el contrario esa comunidad indígena perecería si se tomase una decisión adversa a su particular forma de entender el mundo.

Por cierto, ¿la Corte Constitucional ante este caso podría hacer algo mejor que la administración pública? No se cree.

9 La Corte Constitucional también piensa el caso trágico como caso judicial.

10 Sentencia T-458 de 1997 (M.P.: Eduardo Cifuentes Muñoz). 


\section{CONCLUSIÓN}

Nada obsta para la existencia de casos administrativos trágicos. Su origen radica en la asunción de valores jurídicos en el Estado constitucional y aunque las autoridades administrativas no tienen la última palabra para resolver los casos puestos en su conocimiento o surgidos en la realización de sus funciones, sí deben dar la mejor respuesta posible a todos ellos. Que no sean órganos de cierre en cuestiones constitucionales, no implica que puedan tomar decisiones en cualquier sentido. Así por ejemplo, una autoridad administrativa no podría desligarse de aplicar el principio de menor daño constitucional a causa de no ser juez.

Se deben dejar las prevenciones fundadas frente a las autoridades públicas, y exigirles que tomen las mejores decisiones posibles. Así pues además de los cursos de formación judicial, la argumentación jurídica debe incluirse en todo texto y clase sobre derecho administrativo.

\section{REFERENCIAS BIBLIOGRÁFICAS}

Atienza, M. (1989). Sobre lo razonable en el Derecho. Revista Española de Derecho Constitucional, 27, 93 a 110.

Atienza, M. (2004) Sobre el control de la discrecionalidad administrativa: comentarios a una polémica. Cuestiones Judiciales (pp. 39-71). Fontamara, México D.F.

Atienza, M. (2005). Las razones del derecho. Teorías de la argumentación jurídica. México D.F: Universidad Nacional Autónoma de México.

Atienza, M. (2007). ¿Un caso trágico? Recuperado de http://www.diarioinformacion.com/secciones/noticiaOpinion.jsp?pRe $\mathrm{f}=1939 \_8 \_597011 \_$Opinion-caso-tragico

Atienza, M. (2010a). Argumentación y Constitución. En: Vargas, L. (Coord.). Interpretación constitucional (pp. 67-122). Bogotá: Universidad Libre.

Atienza, M. (2010b).El Derecho como argumentación. Barcelona: Ariel. 
Atienza, M. (2010c). Los límites de la interpretación constitucional. De nuevo sobre los casos trágicos. En: Vargas, L. (Coord.). Interpretación constitucional (pp. 125-155). Bogotá: Universidad Libre.

Atienza, M.(2013).Curso de argumentación jurídica. Madrid: Trotta.

Atienza, M. (2014). Una filosofía del Derecho para el mundo latino. Otra vuelta de tuerca. En: $2^{\circ}$ Congreso Internacional de Filosofía, Hermenéutica Jurídica y Argumentación Jurídica. Bucaramanga, Colombia: Universidad Pontificia Bolivariana-Seccional Bucaramanga.

Atienza, M. \& Ruíz Manero, J. (2004). Las piezas del derecho. Barcelona: Ariel.

Atienza, M. \& Ruíz Manero, J. (2004). Marxismo y Filosofía del Derecho. México D.F.: Fontamara.

Bernal Pulido, C. (2007). El principio de proporcionalidad y los derechos fundamentales. Madrid: Centro de Estudios Políticos y Constitucionales.

Consejo de Estado. Sala de lo Contencioso Administrativo. Sección Segunda. Subsección "A". C.P.: Gustavo Eduardo Gómez Aranguren. Sentencia del 12 de octubre de 2011. Rad.: 25000-23-25-000-200801127-01(0292-11). Isaac Sánchez Gómez Vs. CAJANAL.

Corte Constitucional. Sentencia C -878 de 2011 (M.P.: Juan Carlos Henao Pérez).

Corte Suprema de los Estados Unidos. Caso bBrown vs. Allen. 344 U.S. 443,540 (1953).

Gusastini, R. (2001). Estudios de teoría constitucional. México D.F.: Fontamara.

Gusastini, R. (2007). Ponderación: Un análisis de los conflictos entre principios constitucionales. Palestra del Tribunal Constitucional. 08, 631-637.

Haberle, P. (2004). El Estado constitucional. México D.F: Universidad Nacional Autónoma de México. 
Ruíz Manero, J. (2005). Principios, objetivos y derechos. Otra vuelta de tuerca. DOXA, Cuadernos de Filosofía del Derecho, (28), 341-365.

Sarmiento, D. (2007). El principio de proporcionalidad en el Derecho administrativo. Un análisis jurídico desde el Derecho español. Bogotá: Universidad Externado de Colombia.

Tribunal Administrativo de Santander. M.P.: Solange Blanco Villamizar. Sentencia del 28 de septiembre de 2011. Rad.: 680012331000-2010-00441-00 (SN). Edgar Suarez y Pedro Nilson Amaya Vs. Municipio de Bucaramanga.

Zagrebelsky, G. (2011). El derecho dúctil. Madrid: Trotta.

Zucca, L. (2011). Los conflictos de derechos fundamentales como dilemas constitucionales: En: Moreso, J. y Ferrer, J. (Dirs.). Dilemas constitucionales: un debate sobre sus aspectos jurídicos y morales (pp. 9-36). Madrid: Marcial Pons. 